\title{
USE OF AMBIENT VIBRATION MEASUREMENTS IN ESTABLISHING THE DYNAMIC CHARACTERISTICS OF RC ELEVATED WATER TANKS
}

\author{
Sreenivas Sarma .P' ${ }^{1}$, Murali Krishna . $\mathbf{N}^{2}$, Chandra Sekaran A.R $\mathbf{R}^{3}$ \\ ${ }^{1}$ Professor and Head, Civil Engineering Department, CBIT, Hyderabad \\ ${ }^{2}$ Professor, Civil Engineering Department, UCE (A), Osmania University \\ ${ }^{3}$ Former Professor, IIT Roorkee and Former visiting Professor, Osmania University
}

\begin{abstract}
Reinforced Concrete elevated water tanks are among the most common life line structures that are vulnerable to damage during seismicity. Many earthquakes of even recent times have shown evidence of failure of such structures. While physically, the reasons for the failure of these tanks appear to be the failure of any of their components, inadequate understanding of the dynamic behavior of the tanks is implicitly the cause of such failures. It is in this context that there is a great need to establish the dynamic characteristics of these structures. With the advent of latest technology, it is now possible to measure the ambient vibrations of structures, with precision .

This paper presents the developments in the field of ambient vibration measurements of structures, outlines the general use of these measurements to structures and focuses on it's application to elevated water tanks. Experiences from the experimental program conducted on several RC elevated water tanks in the twin cities of Hyderabad and Secunderabad, are shared. It is envisaged that the use of ambient vibration measurements of elevated water tanks will go a long way in establishing their dynamic characteristics and in performing their seismic analysis and design with a better comprehension .
\end{abstract}

Keywords: Ambient vibration measurements, RC elevated water tanks, Dynamic characteristics, Seismic analysis and design

\section{INTRODUCTION}

Water tanks come under life line structures and are therefore very crucial, particularly in the context of earthquake related disasters . Failures of many elevated water tanks, both staging and shaft supported, were evidenced in the past earthquakes raising concern of the structural engineering fraternity. The great Chilean earthquake of 1960,the Nigata earthquake of 1964,Alaska earthquake of 1964, Imperial valley earthquake of 1979,Coalinga earthquake of 1983 , Loma Prieta earthquake of 1989 , Landera earthquake of 1992 , Northridge earthquake of 1994 , Kocaeli earthquake of 1999 , The Bhuj earthquake of 2001 ,Maule - Chile earthquake of 2010 ,Christ church earthquake of 2011 , and the Great east Japan earthquake of 2011 have proved beyond doubt the vulnerability of all types of tank structures to the ill effects of seismic forces .

\subsection{Failure Mechanisms of Liquid Storage Tanks}

Liquid storage tanks involve various modes of failure mechanisms. Past observations of the seismic performances of the liquid storage tanks have revealed that tank failures are manifested in a wide variety of ways. In fact a wide variety of failure mechanisms are possible, depending upon the configuration of tank geometry, possible fluid-structuresoil interaction, and a lot of other factors such as the tank material, type of support structure, etc. On the other hand, characteristics of earthquakes also significantly influence the response of liquid storage tanks. Failure modes of rectangular tank are significantly different from those of cylindrical, spherical, and conical tanks for that matter. Similarly, the failure patterns for rigid tank considerably differ from those for flexible tanks. Same is the case for on grade, below grade, and above grade or elevated tanks. Different combinations of above possible parameters make the failure mechanism all the more complex.

\subsection{Need for the use of Ambient Vibrations}

Proper estimation of hydrodynamic pressure and the response of the liquid storage structure to it , requires a rigorous fluid-structure interaction analysis, which can properly model the fluid, the structure and their interaction .Housner developed a simplified model for estimating the hydro dynamic pressures in water tanks, considering the fluid structure interaction. In the mechanical analogue of tank-liquid system developed by him, the liquid is divided in two parts as, impulsive liquid and convective liquid. The impulsive liquid moves along with the tank wall, as it is rigidly connected and the convective and sloshing liquid moves relative to tank wall as it under goes sloshing motion. 
However, the dynamic behavior of a particular tank structure depends on it's dynamic characteristics which very much depend on the material and structural properties . Identification of these dynamic characteristics is the key factor in developing proper numerical models . Time period and Frequency are the two important parameters of the structure that can depict it's dynamic behavior .

In the good old days, the structures such as a huge liquid storage tank were used to be pulled by a heavy vehicle tied to the structure, to trigger vibrations that are amenable for physical measurement . The process was not only laborious but also involved lot of risk to the structural safety. Therefore the need for measuring ambient vibrations of a structure without risking it's safety and with a great relative ease, is imperative .

\section{DEVELOPMENTS IN THE FIELD OF} AMBIENT VIBRATION MEASUREMENTS

Ambient vibration testing has been in use for the last 80 years in California .Carder(1936) has started using these tests for measuring the fundamental time periods of buildings . Later on Crawford and Ward ( 1964 ) have shown that these tests can be used for determining the lowest frequencies and modes of vibration of full scale structures . Trifunac (1972) compared the results of Ambient vibration survey and Forced vibration survey for two steel framed buildings of 22 and 39 stories respectively. Udwadia and Trifunac ( 1973 ) have discussed the changes in ambient vibration response of four different types of buildings, before and after an earthquake. Ambient vibration surveys were also used by Luco et.al.(1986) and Wong et.al.(1988) to resolve the contradictory interpretations of the significance of soil structure interaction and of the causes of non-linearity of observed response of the buildings to strong earthquake excitation . Mendoza et.al (1991) and Kadakkal et,al (1996) have used these studies for in depth investigations on the changes in structural properties and towards further development of structural identification methods . Taskov and Krstevska ( 1998 ) along with many others during 90s have involved ambient vibration studies in the identification of natural frequencies, modes shapes of vibration and equivalent viscous damping parameters of various full scale structures . Brownjhon et.al. ( 2000 ) have used these studies for modeling bridges . Ivanovic et.al. have applied these studies extensively for monitoring the changes between system frequencies of small and large response amplitudes. An extensive review of the applications of ambient vibration tests was presented by Ivanovic, Trifunac and Todorovsky ( 2000 ). Gilles and McClure (2008) used the ambient vibration studies for creating a data base for periods of buildings in Montreal . Reports on full scale experimental study on ambient vibration monitoring of an instrumented retaining wall were presented by Dey ( 2015 ). A new concept of development of Citizen sensor network using Ubiquitous smart phones for Structural Health Monitoring and Post-event damage assessment applications was presented by Maria Feng et.al. ( 2015 ).

\subsection{Applications to Liquid Storage Tanks}

Livaoglu R and Dogangun A ( 2008 ) have presented an example of ambient and forced vibration studies on elevated water tank, to understand their dynamic performance .Muthu Vijay P and Amar Prakash ( 2008 ) presented an analysis of sloshing impact on the performance of.elevated water tanks with special focus on Intze type of tanks .The behavior of Elevated RC tanks subjected to artificial ground motion ,was presented by Gareane et.al. ( 2011 ). Moslem amiri et.al. (2011) performed numerical (FEM ) and experimental investigations on a fixed roof Cylindrical liquid container and found that the natural frequencies found either way were in closer agreement .In-situ measurements of of ambient vibrations of several elevated RC water tanks of water heights at 30-40 meters by Lopes H.M. and Oliveira C.S ( 2012 ) to determine the main frequencies of vibrations, modal shapes and damping values for calibrating the analytical models .

\section{AMBIENT VIBRATION TESTING (AVT)}

The response of the structure to" ambient " excitation sources like wind, traffic on or beneath the structure and micro tremors is recorded, in this type of testing. The main components of the equipment for this type of testing consists of a sensor ( uni-axial or Triaxial), a Data acquisition system and a data processing unit . Normally, when a structure is subjected to ambient excitation, it will respond strongest near it's natural frequencies. These frequencies can be identified from the peaks in the power spectral densities computed for the individual acceleration time histories. The recorded accelerations are analysed using programs specifically developed for the analysis of ambient vibration data. Among various such software, DADisp is one of the popular ones . A typical data acquisition system along with the sensors is shown in figure -1 .

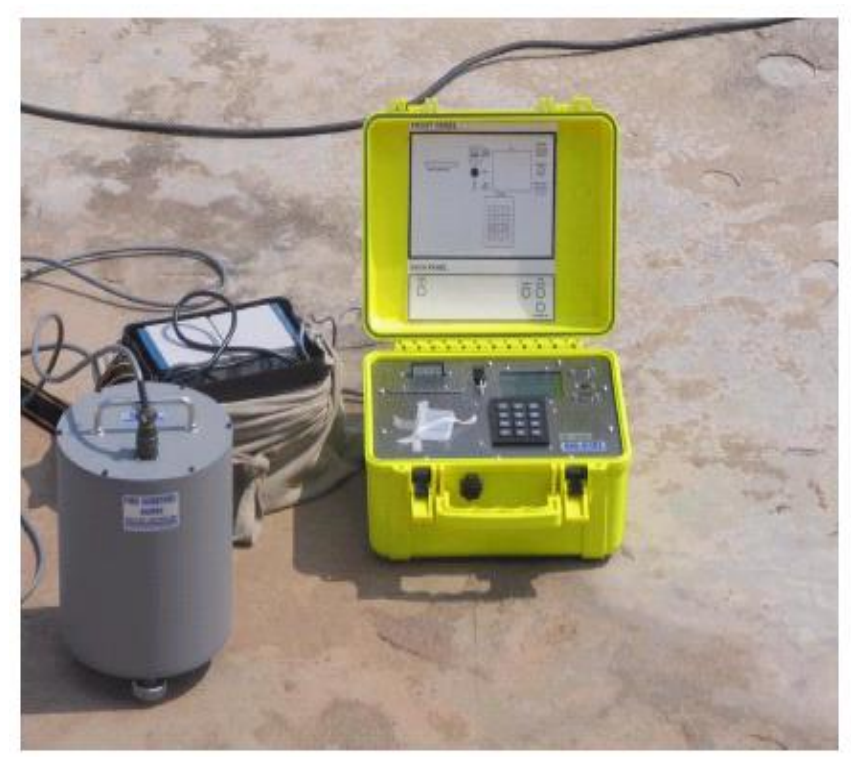

Fig -1: Figure-1: Data acquisition system and Sensors of a typical portable AVT equipment 


\section{USE OF AVT FOR ELEVATED RC WATER TANKS}

Ambient vibration tests were conducted for seventeen elevated RC tanks in the twin cities of Hyderabad and Secunderabad, the details of which are listed in table- 1 .

The ambient vibration data for all these tanks was analysed using DADiSP and their natural frequencies were found . Analytical models of these tanks were also prepared using standard commercially available software and were calibrated to match the natural frequencies obtained from AVT results. Seismic analysis was performed on these calibrated models to know their performance under seismic loads .

\section{CONCLUSION}

1. Inadequate understanding of the dynamic behavior of the elevated liquid storage tanks is implicitly the cause of their failures during earthquakes. It is in this context that there is a great need to establish the dynamic characteristics of these structures. With the advent of latest technology, it is now possible to measure the ambient vibrations of structures, with precision .

2. Use of ambient vibration measurements of elevated water tanks will go a long way in establishing their dynamic characteristics and in performing their seismic analysis and design with a better comprehension .

\section{REFERENCES}

[1]. Ivanovic S.S et.al ( 2000 ), “ Ambient vibration tests of Structures - A review “, ISET Journal of Earthquake Technology, Paperno.407, Vol.37, No.4, December 2000, pp.165-197

[2]. Livaoglu R and Dogangun A ( 2010 ) “ An example of Ambient and Forced vibration tests for understanding of Structural performance of elevated water tanks ", 14th ECEE, Ohrid

[3]. Lopes H.M and Oliveira C.V (2012), “ Use of In-Situ Dynamic measurements to calibrate analytical models of RC elevated water tanks “, Shock and Vibration (19), pp: $903-$ 914

[4]. Feng Maria et.al. ( 2015 ) "Citizen Sensors for SHM : Use of accelerometer data for smart phones, Sensors ,www.mdpi.com/journals/sensors

\section{BIOGRAPHIES}

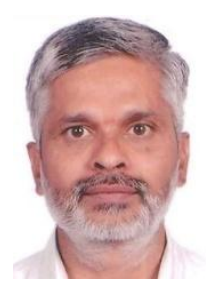

Sreenivas Sarma. P is currently the Head of Civil Engineering department at CBIT. He has 32 years of teaching experience with a simultaneous exposure to the practicing field of Civil Engineering. He has special expertise in retrofitting of structures with a special focus on seismic retrofitting

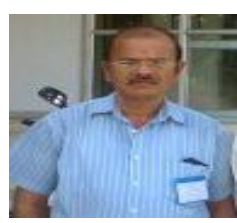

Murali Krishna . N. is presently a professor in the department of Civil Engineering at University college of Engg, Osmania University.

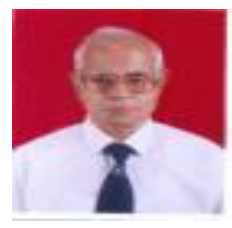

Chandrasekaran A.R., is a former professor in the department of Civil Engineering at IIT Roorkee and also served as a Visiting Professor at University College of Engg, Osmania University 
Table 1: Details of water tanks on which AVT were conducted

\begin{tabular}{|c|c|c|c|c|c|c|c|}
\hline $\begin{array}{l}\text { Location \& Name of the } \\
\text { tank }\end{array}$ & Tank type & $\begin{array}{l}\text { Capacity } \\
\text { (Lit.) }\end{array}$ & $\begin{array}{l}\text { Ht.of } \\
\text { staging }(m)\end{array}$ & $\begin{array}{l}\text { No.of } \\
\text { int.levels }\end{array}$ & $\begin{array}{l}\text { No. of } \\
\text { col. }\end{array}$ & Col. Details & Water Level \\
\hline $\begin{array}{l}\text { CR Enclave,LB } \\
\text { Nagar,Hyd }\end{array}$ & Cylindrical & 30000 & 8.7 & 3 & 4 & $0.3 \mathrm{mx} 0.3 \mathrm{~m}$ & empty \\
\hline $\begin{array}{l}\text { Rly.off. } \\
\text { club,mettuguda,Hyd }\end{array}$ & Intz & 284,000 & 9 & 3 & 8 & $.525 \mathrm{mx} .525 \mathrm{~m}$ & empty \\
\hline Tarnaka $\mathrm{x}$ roads, Hyd & Cylindrical & $1,091,000$ & 9 & 3 & $24(6+6+12)$ & $.23 \mathrm{mx} .45 \mathrm{~m}$ & empty \\
\hline Malkajgiri(East),Hyd & Intz & 60000 & 9 & 3 & 8 & $.55 \mathrm{mx} .55 \mathrm{~m}$ & empty \\
\hline Malkajgiri(west),Hyd & Intz & 40000 & 6 & 2 & 8 & $.55 \mathrm{mx} .55 \mathrm{~m}$ & empty \\
\hline Malkajgiri(Central),Hyd & Intz & 40000 & 6 & 2 & 8 & $.55 \mathrm{mx} .55 \mathrm{~m}$ & empty \\
\hline Malkajgiri(Central),Hyd & Intz & 40000 & 6 & 2 & 8 & $.55 \mathrm{mx} .55 \mathrm{~m}$ & Full \\
\hline Malkajgiri(Central),Hyd & Intz & 40000 & 6 & 2 & 8 & $.55 \mathrm{mx} .55 \mathrm{~m}$ & Half \\
\hline Malkajgiri(Central),Hyd & Intz & 40000 & 6 & 2 & 8 & $.55 \mathrm{mx} .55 \mathrm{~m}$ & quarter ht. \\
\hline North Lalaguda,Hyd & Cylindrical & $1,091,000$ & 9 & 3 & $24(6+6+12)$ & $.23 \mathrm{mx} .45 \mathrm{~m}$ & empty \\
\hline SV Nagar,Hyd & Cylindrical & 60000 & 9 & 3 & 6 & $.3 \mathrm{mx} .3 \mathrm{~m}$ & empty \\
\hline Nagaram(ARWS),Hyd & Cylindrical & 90000 & 9 & 3 & 6 & $.3 \mathrm{mx} .3 \mathrm{~m}$ & Half \\
\hline $\begin{array}{l}\text { Ayyappa } \\
\text { colony,D'guda,Hyd }\end{array}$ & Cylindrical & 60000 & 9 & 3 & 4 & $.3 \mathrm{mx} .3 \mathrm{~m}$ & empty \\
\hline $\begin{array}{l}\text { Dammaiguda } \\
\text { village,Hyd }\end{array}$ & Cylindrical & 90000 & 9 & 3 & 6 & $.3 \mathrm{mx} .3 \mathrm{~m}$ & empty \\
\hline Sahara Estates,Hyd & Funicular & 500000 & 12 & 4 & 8 & $.5 \mathrm{mx} .5 \mathrm{~m}$ & 463636lit(17') \\
\hline Urdu University,Hyd & $\begin{array}{l}\text { Shaft, } \\
\text { funicular }\end{array}$ & 200000 & $\begin{array}{l}\text { (Ht. of } \\
\text { Shaft) } 30 \\
30\end{array}$ & 0 & 0 & $.2 \mathrm{mthick}$ & empty \\
\hline
\end{tabular}

